\title{
The frequency, causes and timing of death within 30 days of a first stroke: the Oxfordshire Community Stroke Project
}

\author{
John Bamford, Martin Dennis, Peter Sandercock, John Burn, Charles Warlow
} Abstract
In a prospective, community-based
study of 675 consecutive patients with a
first-ever stroke, of whom over $90 \%$ had
computed tomography (CT) and/or
necropsy examinations, 129 deaths
occurred within 30 days of the onset of
symptoms, a case fatality rate (CFR) of
$19 \%$. The 30 day CFR for patients with
cerebral infarction was $10 \%$ (57 of 545),
for primary intracerebral haemorrhage $52 \%$ (34 of 66), for subarachnoid haemorrhage $45 \%$ (15 of 33) and for those of uncertain pathological type $74 \%$ (23 of 31). The CFR for patients who had been functionally dependent pre-stroke was $33 \%$ compared with $17 \%$ for those who had been independent pre-stroke. The age-adjusted relative risk of death for patients who had been functionally dependent pre-stroke was not significantly greater $(1 \cdot 8,95 \%$ confidence interval 0 to $4 \cdot 3$ ). There was a significant trend for CFR to increase with age (Chi square for trend $=4.0, p<0.05)$. This relationship was found in those patients who had been functionally independent prestroke (Chi square for trend $=7 \cdot 9, \mathbf{p}<$ 0.005 ) but not in those who had been dependent pre-stroke (Chi square for trend $=0.5$, NS). The pattern of increasing CFR with increasing age amongst those who had been independent prestroke was seen particularly in patients with cerebral infarction (Chi square for trend $=8.6, p<0.005)$. The age-adjusted relative risk of death for patients with cerebral infarction who had been functionally dependent pre-stroke was $2 \cdot 2$ (95\% confidence interval $1 \cdot 2$ to $4 \cdot 1)$. Fifty three percent of all deaths within 30 days of stroke were due to the direct neurological sequelae of the stroke. Patients with primary intracerebral or subarachnoid haemorrhages were significantly more likely to die in this way than those with cerebral infarction (relative risk $4 \cdot 1 ; 95 \%$ confidence interval $3 \cdot 4-4 \cdot 9$ ) and $56 \%$ of such deaths occurred within 72 hours of onset. In patients with cerebral infarction, $51 \%$ of deaths were due to complications of immobility (for example, pneumonia, pulmonary embolism) and these were more likely to occur after the first week. These findings have implications for clinical practice and the planning of clinical trials.
There is some evidence that the case fatality rate (CFR) in the first few weeks after a stroke has declined in recent years. ${ }^{1}$ It is not clear whether this reduction has been caused by changes in management but it has been noted that the decline was most evident between five and 21 days post stroke. ${ }^{2}$ This suggests that it is deaths from the complications of immobility rather than those due to the direct neurological damage that have been reduced. Detailed information concerning the timing and cause of death in unbiased groups of patients where the pathological type of stroke is known accurately is scarce. New therapies such as fibrinolysis may have a significant effect on survival and therefore death should obviously be included as a major endpoint in future stroke treatment trials. We have already reported the value of accurate epidemiological data in planning a trial of secondary stroke prevention ${ }^{3}$ and now wish to report data which might be used to plan trials of treatment to prevent death after an acute stroke. We have analysed the frequency, causes and timing of early death in patients who were registered with a large, prospective, community-based study of first-ever stroke. ${ }^{4}$ Over $90 \%$ of patients had a CT scan or necropsy and this allowed accurate correlations to be made with the pathological type of stroke.

\section{Methods}

The detailed methodology of the Oxfordshire Community Stroke Project (OCSP) has been reported previously. ${ }^{45}$ Briefly, all first-ever in a lifetime strokes presenting to medical attention during a four year period in a population of approximately 105000 people were registered with the study. Patients were assessed as soon as possible after the event by a study neurologist, whether or not they were admitted to hospital. At the time of this initial assessment an estimate of the degree of pre-stroke handicap was made from all available information. A modified version of the Rankin scale was used.$^{67}$ For the purposes of this study the scale was collapsed into those who were functionally independent before their stroke (Grades $0,1,2$ ) and those who were dependent to some degree on other people (Grades 3, 4, 5). We attempted to obtain CT scan and/or necropsy examinations on all patients to determine the pathological type of stroke accurately. The details of these investigations have been reported previously. ${ }^{5}$

All surviving patients were followed up in 
their place of residence by our research nurses. If a patient died, the hospital and general practitioner records were scrutinised and, if possible, the details were discussed with the doctor who had attended the patient at the time of death. This information, together with the details of any necropsy examination, was discussed at a regular meeting of the members of the project team and the cause of death was assigned to one of the following categories:

1 Death due to the direct neurological sequelae of the first stroke-if there was necropsy evidence of trans-tentorial herniation or if the clinical course immediately before death was typical of rostro-caudal brainstem compression; if there had been direct disruption of brainstem function by infra-tentorial strokes or if such strokes had produced acute obstructive hydrocephalus.

2 Death due to the direct neurological sequelae (as above) of a recurrent stroke (NB the first stroke must have occurred in the study period).

3 Death definitely due to cardiac disease-if the clinical diagnosis based on history and examination included conditions such as acute myocardial infarction, cardiac dysrhythmias or cardiac failure and was supported by ECG, cardiac enzymes, chest radiography or necropsy findings.

4 Death probably due to cardiac disease-as above but based on the findings of the clinical history and examination alone. This included cases of sudden unexpected death.

5 Death due to the complications of immobility, for example bronchopneumonia, pulmonary embolus and sepsis.

6 Death unrelated to the stroke, for example, cancer, suicides, accidents.

This report deals with those deaths which occurred within 30 days of the onset of the firstever stroke (day 1 represents the day of the stroke). This period was chosen because a) it. allowed comparison with other large community-based studies b) it corresponded with the flattening of the survival curve ${ }^{5}$ and c) it coincided with the first follow up visit by the OCSP research nurses.

Statistical analysis included age-adjusted relative risks, ${ }^{8}$ odds ratios, ${ }^{9}$ and Chi square for positive trend. ${ }^{10}$

\section{Results}

During the four year study period 675 cases of first-ever stroke were registered with the OCSP of which $545(81 \%)$ were due to cerebral infarction (CI), $66(10 \%)$ to primary intracerebral haemorrhage (PICH), $33(5 \%)$ to subarachnoid haemorrhage (SAH) and $31(5 \%)$ were of uncertain pathological type (UNC). ${ }^{5}$ Before the stroke, $572(85 \%)$ patients had been functionally independent whilst $103(15 \%)$ had been unable to live independently because of some non-stroke problem such as arthritis, dementia etc. No patients were lost to follow up. There were $129(19 \%)$ deaths within 30 days of the stroke of whom $56(43 \%)$ had a necropsy examination.

\section{Age and pre-stroke handicap}

The age-specific 30 day case fatality rate (CFR) according to pathological type of stroke is shown in table 1 . When all stroke types were combined the CFR increased with increasing age (Chi square for trend $=4.0, p<0.05$ ). The CFR was higher amongst those patients who had been dependent pre-stroke (34 of 103$33 \%$ ) than those who had been independent ( 95 of $572-17 \%)$; the age-adjusted relative risk was $1.8(95 \%$ confidence interval 0 to 4.3$)$. The rise in CFR with increasing age was statistically significant in those who had been independent pre-stroke (Chi square for trend $=7 \cdot 9, \mathrm{p}<$ 0.005 ) but not in those who had been dependent (Chi square for trend $=0.5$ ).

If the analysis is restricted to those patients who had a cerebral infarct, the relative risk of death was $2 \cdot 2$ times greater for those who had been functionally dependent pre-stroke $(95 \%$

Table 1 Age specific case fatality rates for the different pathological types of stroke by level of pre-stroke handicap

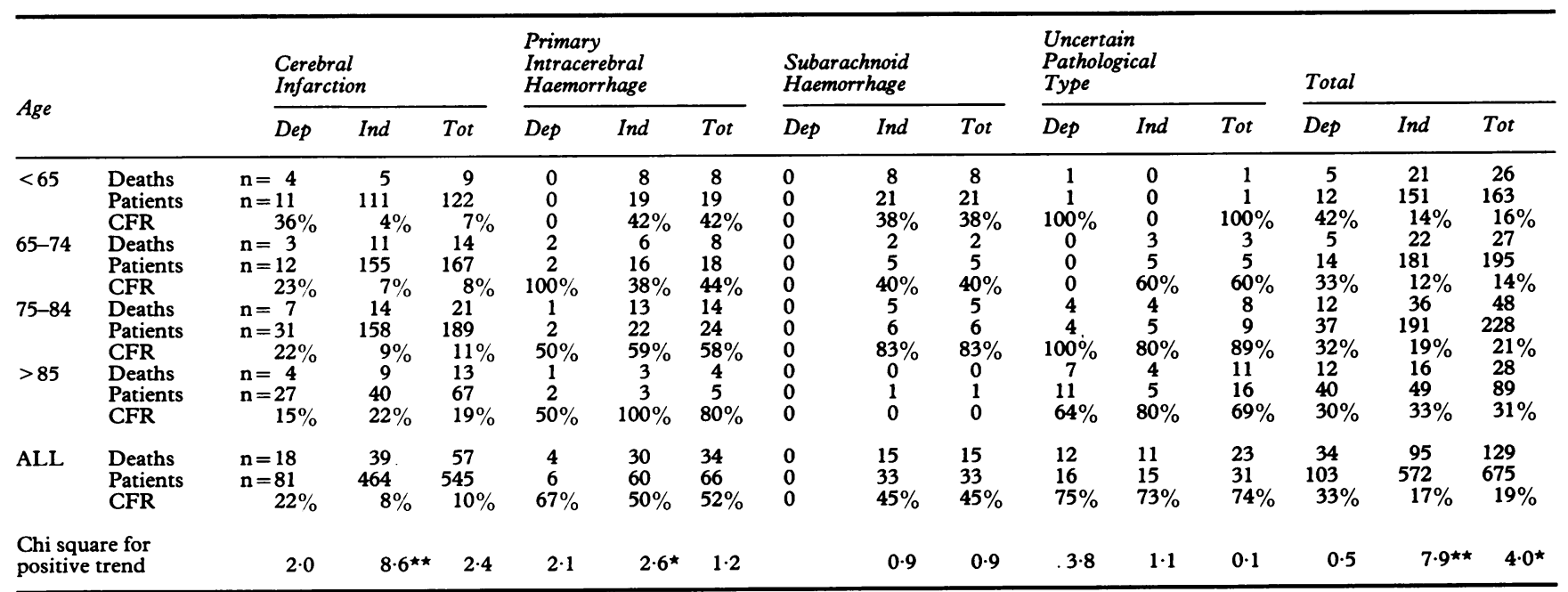

CFR = case fatality rate.

Ind $=$ functionally independent pre-stroke (Rankin grades $0,1,2$ )

Dep $=$ functionally dependent pre-stroke (Rankin grades $3,4,5$ )

${ }^{\star} \mathrm{p}<0.05$

$\star \mathrm{p}<0.005$ 
Table 2 Age specific causes of death

\begin{tabular}{llllllr}
\hline \multicolumn{2}{l}{ Age group } & Neuro & Immob & Cardiac & Other & Total \\
\hline$<65$ & $(\mathrm{n}=163)$ & $16(62 \%)$ & $6(23 \%)$ & $1(4 \%)$ & $3(12 \%)$ & 26 \\
$65-74$ & $(\mathrm{n}=195)$ & $16(59 \%)$ & $9(33 \%)$ & $2(7 \%)$ & $0(0)$ & 27 \\
$75-84$ & $(\mathrm{n}=228)$ & $25(52 \%)$ & $16(33 \%)$ & $5(10 \%)$ & $2(4 \%)$ & 48 \\
$>85$ & $(\mathrm{n}=89)$ & $12(43 \%)$ & $14(50 \%)$ & $1(4 \%)$ & $1(4 \%)$ & 28 \\
Total & $(\mathrm{n}=675)$ & $69(53 \%)$ & $45(35 \%)$ & $9(7 \%)$ & $6(5 \%)$ & 129 \\
\hline
\end{tabular}

Cause of death: Neuro = due to direct neurological sequelae

Immob $=$ due to complications of immobility

confidence interval $1 \cdot 2$ to $4 \cdot 1$ ). The trend of increasing CFR with age was only present in those who were independent pre-stroke (table 1).

\section{Timing and cause of death}

Eighty of the 129 deaths (62\%) occurred either on the day of the stroke (referred to as day 1) or in the first seven complete days after stroke, and $27(21 \%)$ in the subsequent seven days. There were $22(17 \%)$ deaths between 16 and 30 days post stroke. Death was ascribed to: the direct neurological sequelae of the stroke in 69 cases $(53 \%, 95 \%$ confidence interval $45 \%$ to $62 \%$ ) of which four were recurrent strokes; to the complications of stroke related disability in 45 cases $(35 \%, 27 \%$ to $43 \%$ ); to cardiac disease in nine cases $(7 \%)$, and to other causes in six cases $(5 \%)$.

The age-specific causes of death are shown in table 2. With increasing age there was a decreasing proportion of neurological deaths and an increasing proportion of deaths due to immobility. However, neither trend was statistically significant, possibly because of the small numbers in each group (Chi square for trendneurological deaths $=2 \cdot 2, \mathrm{p}=0.138$; deaths due to immobility $=3.69, \mathrm{p}=0.054$ ).

The cause of death according to pathological type of stroke and level of pre-stroke handicap is shown in table 3. Patients who had a PICH were significantly more likely to die from the direct neurological sequelae ( 25 of $34,74 \%$ ) than those with CI (16 of $57,28 \%$ ) (ageadjusted relative risk $=4 \cdot 1 ; 95 \%$ confidence interval 3.4 to 4.9 ) and $87 \%$ of deaths in patients who had a SAH were due to neurological causes. Indeed, all deaths due to direct neurological damage in patients less than 65 years of age were in patients with either
PICH or SAH. Only 16 of $545(3 \%)$ patients with CI actually died from the direct neurological sequelae. Furthermore, five of these 16 had been functionally dependent before the stroke. One might have expected the excess CFR amongst those patients with CI who had been dependent pre-stroke to have been caused by an increased proportion of deaths due to the complications of immobility but the age-adjusted relative risk was 0.97; (95\% confidence interval 0 to $13 \cdot 7$ ).

The time to death for those dying from the direct neurological sequelae of their first stroke is shown in fig 1. The only "neurological" deaths more than seven days after the first stroke followed a recurrent stroke- on days 13 (SAH), 15 (PICH), $17(\mathrm{CI})$, and 24 (SAH). Significantly more deaths from haemorrhagic strokes occurred within the first 12 hours (16 of $49[33 \%])$ of which four were SAH and 12 PICH, compared with one of 57 [2\%] cases of $\mathrm{CI}$ (Odds ratio $27 ; 95 \%$ confidence interval 6 to 134). Of the 12 patients dying from PICH, four were found dead in bed, three died within four hours of the first symptom and the other five within 12 hours. Of the eight who were alive when first found, two were dead on arrival at hospital, one was cared for at home throughout and the other five were all in hospital within one hour of the first symptom. None had neurosurgical procedures performed. Of the four patients dying from their first SAH, one was found dead and the others died four, six and eight hours after the onset of symptoms. It is important to note than six of the $15(40 \%)$ patients who died from the neurological sequelae of their first cerebral infarct had lesions in the brainstem, their deaths occurring on day two (three cases), day. three (one case) and day four (two cases). Only three patients

Table 3 Cause of death by pathological type of stroke and pre-stroke handicap

\begin{tabular}{|c|c|c|c|c|c|c|c|c|c|c|c|c|c|c|c|c|}
\hline \multirow[b]{2}{*}{ Cause of death } & & \multicolumn{3}{|c|}{$\begin{array}{l}\text { Cerebral } \\
\text { Infarction }\end{array}$} & \multicolumn{3}{|c|}{$\begin{array}{l}\text { Primary } \\
\text { Intracerebral } \\
\text { Haemorrhage }\end{array}$} & \multicolumn{3}{|c|}{$\begin{array}{l}\text { Subarachnoid } \\
\text { Haemorrhage }\end{array}$} & \multicolumn{3}{|c|}{$\begin{array}{l}\text { Uncertain } \\
\text { Pathological } \\
\text { Type }\end{array}$} & \multicolumn{3}{|l|}{ Total } \\
\hline & & Ind & Dep & Tot & Ind & Dep & Tot & Ind & Dep & Tot & Ind & Dep & Tot & Ind & Dep & Tot \\
\hline $\begin{array}{l}\text { Neurological } \\
\text { Sequelae } \\
\text { Complications }\end{array}$ & $\begin{array}{r}\mathrm{n}= \\
\%=\end{array}$ & $\begin{array}{l}11 \\
28 \%\end{array}$ & $\begin{array}{c}5 \\
28 \%\end{array}$ & $\begin{array}{l}16 \\
28 \%\end{array}$ & $\begin{array}{l}24 \\
80 \%\end{array}$ & $25 \%$ & $\begin{array}{l}25 \\
74 \%\end{array}$ & $\begin{array}{l}13 \\
87 \%\end{array}$ & $\begin{array}{l}0 \\
0\end{array}$ & $\begin{array}{l}13 \\
87 \%\end{array}$ & $\begin{array}{c}8 \\
73 \%\end{array}$ & $\begin{array}{c}7 \\
58 \%\end{array}$ & $\begin{array}{l}15 \\
65 \%\end{array}$ & $\begin{array}{l}56 \\
59 \%\end{array}$ & $\begin{array}{l}13 \\
38 \%\end{array}$ & $\begin{array}{l}69 \\
53 \%\end{array}$ \\
\hline $\begin{array}{l}\text { of immobility } \\
\text { Cardiac disease } \\
\text { Other causes }\end{array}$ & $\begin{array}{r}\mathbf{n}= \\
\%= \\
\mathbf{n}= \\
\%= \\
\mathbf{n}= \\
\%=\end{array}$ & $\begin{array}{c}19 \\
49 \% \\
7 \\
18 \% \\
2 \\
5 \%\end{array}$ & $\begin{array}{c}10 \\
56 \% \\
1 \\
6 \% \\
2 \\
11 \%\end{array}$ & $\begin{array}{c}29 \\
51 \% \\
8 \\
14 \% \\
4 \\
7 \%\end{array}$ & $\begin{array}{c}4 \\
13 \% \\
0 \\
0 \\
2 \\
7 \%\end{array}$ & $\begin{array}{c}3 \\
75 \% \\
0 \\
0 \\
0 \\
0\end{array}$ & $\begin{array}{c}7 \\
21 \% \\
0 \\
0 \\
2 \\
6 \%\end{array}$ & $\begin{array}{l}1 \\
7 \% \\
1 \\
7 \% \\
0 \\
0\end{array}$ & $\begin{array}{l}0 \\
0 \\
0 \\
0 \\
0 \\
0\end{array}$ & $\begin{array}{l}1 \\
7 \% \\
1 \\
7 \% \\
0 \\
0\end{array}$ & $\begin{array}{c}3 \\
27 \% \\
0 \\
0 \\
0 \\
0\end{array}$ & $\begin{array}{c}5 \\
42 \% \\
0 \\
0 \\
0 \\
0\end{array}$ & $\begin{array}{c}8 \\
35 \% \\
0 \\
0 \\
0 \\
0\end{array}$ & $\begin{array}{l}27 \\
28 \% \\
8 \\
8 \% \\
\mathbf{4} \% \\
\mathbf{4} \%\end{array}$ & $\begin{array}{c}18 \\
53 \% \\
1 \\
3 \% \\
2 \% \\
6 \%\end{array}$ & $\begin{array}{l}45 \\
35 \% \\
9 \\
7 \% \\
6 \\
6 \%\end{array}$ \\
\hline ALL CAUSES & $\mathbf{n}=$ & 39 & 18 & 57 & 30 & 4 & 34 & 15 & 0 & 15 & 11 & 12 & 23 & 95 & 34 & 129 \\
\hline
\end{tabular}

Ind $=$ functionally independent pre-stroke (Rankin grades $0,1,2)$

Dep = functionally dependent pre-stroke (Rankin grades $3,4,5$ ) 
Figure 1 Timing of deaths due to the direct neurological sequelae of $a$ first stroke according to pathological type.

$C I=$ cerebral infarction $\mathrm{PICH}=$ primary intracerebral haemorrhage $S A H=$ subarachnoid haemorrhage

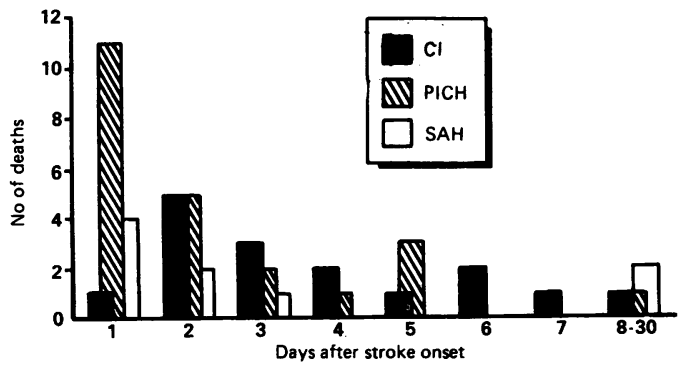

who died were taking aspirin (two $\mathrm{CI}$, one PICH) and only one who had a cerebral infarct was on anticoagulants.

The time to death for those dying from cardiac disease or the complications of immobility is shown in fig 2 . All but one of the nine cardiac deaths occurred in patients with $\mathrm{CI}$ and four $(44 \%)$ had had a recent myocardial infarction before their stroke.

\section{Discussion}

Ascertaining the cause of death

If treatments to reduce death after stroke are to be appropriately targeted on specific pathological processes and then tested adequately, it is vital to know the frequency, mechanisms and timing of deaths in untreated patients. Although many studies have described the proportion of patients who survive after a stroke, little attention has been paid to the specific causes of death, particularly in community-based series. This may well be a reflection of the methodological difficulties which are encountered.

The recognised inaccuracies of death certificates ${ }^{111213}$ mean that, on their own, they are unsuitable for any detailed study. The necropsy also has limitations as the ultimate arbiter of the cause of death, even if a significant proportion of cases can be studied which is unusual. ${ }^{14}$ In the United Kingdom, many patients who die rapidly have a necropsy examination primarily to satisfy the coroner that there are no suspicious circumstances relating to the death. In such cases the brain is often cut fresh and not retained for examination by a neuropathologist. Stroke may be given as the primary cause of death yet the mechanism by which it led to death may not be mentioned. Also, the pathological changes of infarction (either cerebral or cardiac) take hours or even days to appear macroscopically. ${ }^{15}$ Thus the identification of, for example, brainstem infarcts causing death by direct disruption of

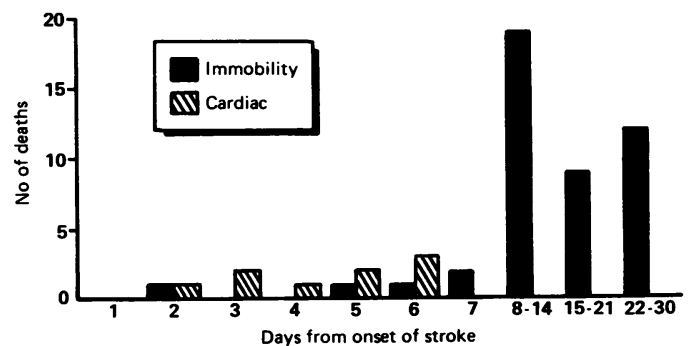

respiratory and cardiovascular "centres", is extemely difficult in the acute phase. Similarly, the extent of infarction visible macroscopically may be considerably less than the total area of affected tissue. A further problem is to identify the cause of death when several different pathological processes are present. Indeed, some authors have simply listed all pathological findings without attempting to identify the most likely cause of death. ${ }^{16}$

In this community-based study we reviewed all the available information, both clinical and pathological, to try and determine which process had been the most important in determining the fatal outcome in every patient. Nevertheless, since a proportion of the patients were elderly and managed at home, and therefore even quite simple investigations were either clinically inappropriate or impractical, we have had to use fairly broad categories. One advantage of hospital-based studies, particularly those that are performed prospectively, is that they may have available the details of serial physical examinations and the results of various investigations performed near the time of death, even though the group of patients will be a potentially biased sample. Therefore, the cause of death may be determined more accurately than for patients who die in the community. Bias may occur in hospital series because patients with more severe deficits (often due to $\mathrm{PICH}$ ) are more likely to be admitted to hospital. ${ }^{17}$ Also, a significant proportion, particularly those with $\mathrm{PICH}$ or SAH, will die before admission is possible. Since attitudes towards hospital admission are likely to vary unpredictably from area to area and with time, particularly if new treatments become available, it is important that planning decisions are made taking all patients with stroke into account. Although community based studies of stroke can avoid this selection bias, no prospective study has previously attempted to determine the likely mechanisms of death within 30 days of the stroke.

\section{Effect of age and pre-stroke handicap}

The trend for the CFR to rise with increasing age was noted by Parrish et $a l^{18}$ in 1966 and has since been reported in a number of communitybased series. ${ }^{19-22}$ Our data suggest that this may only apply to patients who had been functionally independent pre-stroke. Very few patients who had a PICH or SAH had been functionally dependent pre-stroke and therefore this trend is seen most clearly when only cases of cerebral infarction are considered. We have also shown that in patients aged less than 75 years, over half the early deaths occur in patients with either PICH or SAH. Therefore, if treatments aimed at preventing death soon after a cerebral infarct are to be tested, elderly patients who are more likely to have "endpoints" should not be excluded from clinical trials. A potential problem with such a strategy is, as several authors ${ }^{172223}$ have noted, that the proportion of patients who are admitted to hospital declines with increasing,age, thus reducing the number of cases likely to enter a trial. Such patterns
Figure 2 Timing complications of immobility or cardiac disease. 
might alter if a truly effective treatment were available for acute stroke.

Our results confirm that pre-stroke handicap is an adverse prognostic factor for early survival which, amongst patients with cerebral infarction, seems to be independent of age. One might have expected that the excess mortality of those who were handicapped would be due to the complications of immobility but, once age had been taken into account, we were unable to show this although the small numbers meant that the confidence interval was very wide. In the hospital-based necropsy series of Viitanen, Winblad and Asplund ${ }^{24}$ which studied deaths up to three months after a stroke, there was a tendency for those over 75 years of age (who are likely to be more disabled than younger patients) to die from bonchopneumonia rather than from the direct neurological sequelae of the stroke, but this did not reach conventional levels of significance.

\section{Cause and timing of deaths}

a) Strokes due to primary intracerebral or subarachnoid haemorrhage

Necropsy series have demonstrated that intracranial haemorrhages which rupture into the ventricular system frequently result in rapid death, presumably due to the acute rise in intracranial pressure and secondary brainstem haemorrages. ${ }^{25}$ This pattern has been confirmed in community-based studies; for example Furlan $e t a l^{26}$ reported that in Rochester, Minnesota, about $75 \%$ of the deaths from PICH occurred within 72 hours of the onset. The lower proportion $(56 \%)$ in our series, although not significantly different, may be due to the detection of smaller haemorrhages with CT scanning. In a more detailed report from Rochester, ${ }^{27} 35 \%$ of deaths in patients with PICH and $61 \%$ in patients with SAH occurred within 24 hours of the onset compared with only $2 \%$ of deaths in patients with CI (none of which were due to trans-tentorial herniation). In our series the respective figures were 35\% for PICH but only $27 \%$ for SAH, the latter proportion being significantly lower ( $p<$ 0.01 ). This may reflect the more rapid and frequent detection and, presumably, treatment of early complications of SAH such as hydrocephalus with CT scanning. Recent data from Rochester ${ }^{28}$ shows that the CFR from SAH has declined there during the last decade. Phillips et $a l^{7}$ noted that $30 \%$ of the patients who died from a PICH were taking anticoagulants. The number of patients in our study who were taking either anticoagulants or aspirin was very small but no trend towards a higher CFR in this group was noted.

The most detailed hospital-based study published to date was that by Silver et a ${ }^{9}$ though this excluded cases requiring urgent neurosurgical intervention (cases of SAH and cerebellar haematoma) and any who died before reaching hospital. In this series $80 \%$ of the "neurological" deaths in patients with PICH had occurred within 72 hours of onset. However, they suggested that a second peak of deaths occurring at the end of the first week might be due to the development of oedema around the haematoma. The pathological evidence suggests that the oedema around a haematoma only increases for the first three days, ${ }^{25}$ but our results are similar to those of Silver et $a{ }^{29}$ there being a small rise in the number of deaths on the fifth day. There was no clinical evidence from our study that these slightly later deaths might be due to further haemorrhage although those patients who were at home were not under close clinical supervision. Our findings confirm those of other studies where the majority of deaths in patients with PICH or SAH have been due to the direct neurological sequelae of the haemorrhage. ${ }^{24} 29$ Nearly $70 \%$ of such deaths occurred within 72 hours of onset and most of these patients were comatose from soon after the ictus. There is no evidence that surgical intervention in this group is of benefit, presumably because significant structural damage to vital centres is caused at the onset..$^{30}$ Therefore, the number of patients with PICH who are not comatose at presentation but who subsequently die from the neurologial sequelae, and thus who might have been considered for surgical intervention, was very small.

\section{Ischaemic strokes}

Although patients with cerebral infarcts have a much lower CFR than patients with PICH or $\mathrm{SAH}$, they are more frequent and account for almost half of all deaths within 30 days of a first stroke. Moreover, the timing and causes of these deaths are quite different to those in patients with PICH or SAH. In our study, $28 \%$ of early deaths after a first cerebral infarct were due to the direct neurological sequelae and only $16 \%$ were due to trans-tentorial herniation. Experimental, necropsy and radiological evidence suggests that the oedema around a cerebral infarct reaches its maximum between third and fifth days after stroke..$^{25}$ However, in the study of Shaw $e t a l^{31}$ six of the 17 patients died within two days and only two between days three and five. There was a similar finding in the necropsy study of Bounds et $a l^{32}$ where $62 \%$ of the deaths due to transtentorial herniation had occurred within three days of onset. Once again our findings are in keeping with those of Silver et al ${ }^{9}$ who attributed $80 \%$ of deaths in the first week after supratentorial infarction to trans-tentorial herniation with no such deaths on the first day and a peak between the second and sixth days. In our series the only death within 24 hours of onset of a cerebral infarct was a patient who was found dead in bed at home. Regrettably, only a coroner's necropsy was performed and the brain was not sent to a neuropathologist. Cerebral infarction was recorded as the cause of death although no comment was made about trans-tentorial herniation or midline shift. No other cause of death was found and therefore, with some reservation, we placed it in the category of neurological death. We would agree with Silver $e t a l^{29}$ that the discrepancy between the clinical and necropsy studies probably results from an unusual case mix in the latter; for example whilst $50 \%$ of deaths had occurred within three days of onset in the study of 
Bounds $e t a l^{32}$ only $12 \%$ had occurred by this time in the study of Silver et al. $^{29}$

Deaths due to the complications of immobility become frequent after the first week. In the necropsy study of Brown and Glassenberg ${ }^{16}$ all of the patients surviving more than one week had evidence of potentially fatal diseases outside the nervous system. We have considered pneumonia, pulmonary embolism and sepsis together because of the difficulties of distinguishing the first two in patients not under constant medical supervision. Pneumonia has been reported to be almost twice as common a cause of death as pulmonary embolism ${ }^{29}{ }^{32}$ although others have reported the opposite. ${ }^{24}$ Silver et al $^{29}$ described the same temporal pattern of non-neurological deaths in a similar composite group to that in our study.

It has been suggested that a possible value of stroke intensive care units is that the mortality from these complications may be reduced ${ }^{33}$ although it is less clear whether this is at the expense of increased numbers of survivors with persistent major disability. We were unable to comment on the functional status of patients immediately before death but Silver et al ${ }^{9}$ noted that in over $70 \%$ of such cases the patients were severely disabled. If acute treatments aimed at limiting the extent of cerebral infarction become available and are tested in clinical trials, then it would be important to include an assessment of the cause of any deaths in the protocol. However, specific treatments to prevent complications may be of benefit to those with mild or minimal disability. ${ }^{34}$

The results of this study emphasise the different frequency, timing and causes of death between patients with primary intracerebral or subarachnoid haemorrhage and those with cerebral infarction. In the former, the majority of deaths are due to the acute compromise of critical neurological functions whereas in the latter death is more likely to occur because of the complications of immobility. When clinical trials of treatments for acute stroke are being planned, these characteristics should be taken into account.

1 Broderick JP, Phillips SJ, Whisnant JP, O'Fallon WM, Bergstralh EJ. Incidence rate of stroke in the eighties: The end of the decline in stroke? Stroke 1989;20:577-82.

2 Garraway WM, Whisnant JP, Drury I. The changing pattern of survival following stroke. Stroke 1983;14: 699-703.

3 Sandercock P, Warlow C, Bamford J, Peto R, Starkey I. Is a controlled trial of longterm oral anticoagulation in patients with stroke and non-rheumatic atrial fibrillation worthwhile? Lancet 1986;i:788-92.

4 Bamford J, Sandercock P, Dennis $M$, et al. A prospective study of acute cerebrovascular disease in the community: The Oxfordshire Community Stroke Project 1981-86. 1 . Methodology, demography and incident cases of first-ever Methodology, demography and incident cases of first-eve
stroke. J Neurol Neurosurg Psychiatry 1988;51:1373-80.

5 Bamford J, Sandercock P, Dennis M, Burn J, Warlow C. A prospective study of acute cerebrovascular disease in the community: The Oxfordshire Community Stroke Project 1981-86. 2. Incidence, case fatality rates and overall outcome at one year of cerebral infarction, primary intracerebral haemorrhage and subarachnoid haemorrhage. J Neurol Neurosurg Psychiatry 1990;53:16-22.

6 Rankin J. Cerebrovascular accidents in patients over 65 years of age: 2. Prognosis. Scot Med J 1957;2:200-15.

7 Bamford J, Sandercock P, Warlow C. Interobserver agreement for the assessment of handicap in stroke patients. Stroke 1989;20:828.

8 Armitage P. Statistical methods in medical research. Blackwell: Oxford, 1971:427-33.

9 Morris JA, Gardner MJ. Calculating confidence intervals for relative risks, odds ratios and standardised ratios and rate. In: Gardner MJ, Altman DG, eds. Statistics with confidence. London: $\mathrm{Br}$ Med J 1989:50-63.

10 SPSS Inc. Statistical package for the social sciences. New York: McGraw Hill, 1983.

11 Cameron HM, McGoogan E. A prospective study of 1152 hospital autopsies. 1 . Inaccuracies in death certification. $J$ Pathol 1981;133:273-83.

12 Cameron HM, McGoogan E. A prospective study of 1152 hospital autopsies. 2. Analysis of inaccuracies in clinical diagnosis and their significance. J Pathol 1981;133: 285-300.

13 Corwin LI, Wolf PA, Kannel WB, McNamara PM. Accuracy of death certification of stroke: The Framingham study. Stroke 1982;13:818-21.

14 Hughes JT. Necropsies on patients after stroke. $\mathrm{Br} \mathrm{Med} \mathrm{J}$ 1985;291:843.

15 Cappell DF, Anderson JR. Disturbances of the circulation: local ischaemia. Muir's Textbook of Pathology. London: Edward Arnold 1971:172-8.

16 Brown M, Glassenberg M. Mortality factors in patients with acute stroke. JAMA 1973;224:1493-5.

17 Bamford J, Sandercock P, Warlow C, Gray M. Why are patients with acute stroke admitted to hospital? The experience of the Oxfordshire Community Stroke Project. Br Med J 1986;292:1369-72.

18 Parrish HM, Payne GH, Allen WC, Goldner JC, Sauer HI. Mid-Missouri stroke survey: a preliminary report. Miss Med 1966;63:816-21.

19 Aho K, Harmsen P, Hatano S, Marquardsen J, Smirnov VE, Strasser T. Cerebrovascular disease in the community:
Results of the WHO Collaborative Study. Bull WHO 1980;58:113-30.

20 Sacco RL, Wolf PA, Bharucha NE, et al. Subarachnoid haemorrhage and intracerebral haemorrhage: Natural history, prognosis, and precursive factors in the Framinhistory, prognosis, and precursive factors
gham study. Neurology 1984;34:847-54.

21 Herman B, Leyten ACM, van Luijk JH, Frenken CWGM, de Coul O, Schulte BPM. Epidemiology of stroke in Tilburg, The Netherlands. The population-based stroke incidence register: 2 . Incidence, initial clinical picture and medical care, and three week case fatality. Stroke 1982;13:334-9.

22 Bonita R, Beaglehole R, North JDK. Event, incidence and case fatality rates of cerebrovascular disease in Auckland, New Zealand. Am J Epidemiol 1984;120:236-43.

23 Ueda K, Omae T, Hirota Y, et al. Decreasing trend in incidence and mortality from stroke in Hisayama residents, Japan. Stroke 1981;12:154-60.

24 Viitanen M, Winblad B, Asplund K. Autopsy-verified causes of death after stroke. Acta Med Scand 1987:222:401-8.

25 Clasen RA, Huckman MS, Von Roenn KA, Pandolfi S, Laing I, Clasen JR. Time course of cerebral swelling in stroke. A correlative autopsy and CT study. In: CervosNavarro J, Ferszt R, eds. Brain Edema-Advances in Neurology, Vol 28. New York: Raven Press; 1980: 395-412.

26 Furlan AJ, Whisnant JP, Elveback LR. The decreasing incidence of primary intracerebral haemorrhage: A population study. Ann Neurol 1979;5:367-73.

27 Phillips LH, Whisnant JP, Reagan TJ. Sudden death from stroke. Stroke 1977;8:392-5.

28 Ingall TJ, Whisnant JP, Wiebers DO, O'Fallon WM. Has there been a decline in subarachnoid hemorrhage morthere been a decline in subaract

29 Silver FL, Norris JW, Lewis AJ, Hachinski VC. Early mortality following stroke: a prospective review. Stroke 1984;15:492-6.

30 Marshall J. Should spontaneous cerebral haematomas be evacuated and if so when? In: Warlow C, Garfield J, eds. Dilemmas in the management of the neurological patient. Edinburgh: Churchill Livingstone; 1984:54-61.

31 Shaw CM, Alvord EC, Berry RG. Swelling of the brain following ischaemic infarction with arterial occlusion. Arch Neurol 1959;1:161-77.

32 Bounds JV, Weibers DO, Whisnant JP, Okazaki H. Mechanisms and timing of deaths from cerebral infarction. Stroke 1981;12:474-7.

33. Drake WE, Hamilton MJ, Blumenkrantz J. Acute stroke management and patient outcome: The value of neurovasmanagement and patient outcome: The value of

34 McCarthy ST, Turner J. Low-dose subcutaneous heparin in the prevention of deep-vein thrombosis and pulmonary embolism following acute stroke. Age Aging 1986;15:84-8. 